\title{
Coupled best proximity point theorems for proximally $g$-Meir-Keeler type mappings in partially ordered metric spaces
}

\section{Ali Abkar*, Samaneh Ghods and Azizollah Azizi}

"Correspondence: abkar@sci.ikiu.ac.ir Department of Mathematics, Imam Khomeini International University, Qazvin, 34149, Iran

\section{Springer}

\begin{abstract}
In this paper we first introduce the notion of proximally g-Meir-Keeler type mappings, then we study the existence and uniqueness of coupled best proximity points for these mappings. This generalization is in line with Edelstein's generalization of Meir-Keeler type mappings, as well as in line with the recent one used in (Eshaghi Gordji in Math. Probl. Eng. 2012:150363, 2012).
\end{abstract}

MSC: $47 \mathrm{H} 10 ; 54 \mathrm{H} 25 ; 47 \mathrm{~J} 25$

Keywords: coupled best proximity point; proximally g-Meir-Keeler type mapping; proximal mixed strict $g$-monotone property

\section{Introduction}

The Banach contraction principle [1] is a classical and powerful tool in nonlinear analysis. This principle has been generalized in different directions by many authors (see, for example, [2-6] and the references therein). Afterward, Bhaskar and Lakshmikantham [7] introduced the notion of coupled fixed points of a given two-variable mapping $F$. They also established the uniqueness of coupled fixed point for the mapping $F$, and successfully applied their results to the problem of existence and uniqueness of solution for a periodic boundary value problem. Following their lines of research, some authors have extended these results in several directions (see, for instance, $[8,9]$ ).

The well-known best approximation theorem, due to Fan [10], asserts that if $A$ is a nonempty, compact and convex subset of a normed linear space $X$, and $T$ is a continuous mapping from $A$ to $X$, then there exists a point $x \in A$ such that the distance of $x$ to $T x$ is equal to the distance of $T x$ to $A$. Such a point $x$ is called a best approximant of $T$ in $A$. This result was in turn generalized by several authors (see, for example, [11-13], and the references therein).

In the sequel, $X$ is a nonempty set, and $(X, d)$ is a metric space. In [2], Meir and Keeler generalized the well-known Banach contraction principle. In 1969, Meir and Keeler defined weak uniformly strict contraction as follows: given $\epsilon>0$, there exists $\delta>0$ such that

$$
\epsilon \leq d(x, y)<\epsilon+\delta \quad \Longrightarrow \quad d(F x, F y)<\epsilon
$$

(c) 2015 Abkar et al. This article is distributed under the terms of the Creative Commons Attribution 4.0 International License (http://creativecommons.org/licenses/by/4.0/), which permits unrestricted use, distribution, and reproduction in any medium, provided you give appropriate credit to the original author(s) and the source, provide a link to the Creative Commons license, and indicate if changes were made. 
for a self-map $F$ on $X$. They proved that every weakly uniformly strict contraction on a complete metric space $(X, d)$ has a unique fixed point. In this way, they were able to recapture earlier results due to Edelstein, as well as that of Boyd and Wong.

Recently, Eshaghi Gordji et al. [14], defined the generalized $g$-Meir-Keeler type contractions and proved some coupled fixed point theorems under a generalized $g$-Meir-Keelercontractive condition. In this way, they improved results of Bhaskar and Lakshmikantham [7]. We shall recall their definitions here.

Definition 1.1 [14] Let $(X, \leq)$ be a partially ordered set and $d$ be a metric on $X$. Let $F$ : $X \times X \rightarrow X$ and $g: X \rightarrow X$ be two given mappings. We say that $F$ is a generalized $g$-MeirKeeler type contraction if, for every $\epsilon>0$, there exists $\delta(\epsilon)>0$ such that, for all $x, y, u, v \in X$ with $g(x) \leq g(u)$ and $g(y) \geq g(v)$,

$$
\epsilon \leq \frac{1}{2}[d(g(x), g(u))+d(g(y), g(v))]<\epsilon+\delta(\epsilon) \quad \Longrightarrow \quad d(F(x, y), F(u, v))<\epsilon .
$$

They also defined the mixed strict $g$-monotone property.

Definition 1.2 [14] Let $(X, \leq)$ be a partially ordered set and $F: X \times X \rightarrow X$ and $g: X \rightarrow X$ be two given mappings. We say that $F$ has the mixed strict $g$-monotone property if, for any $x, y \in X$,

$$
\begin{array}{ll}
x_{1}, x_{2} \in X, & g\left(x_{1}\right)<g\left(x_{2}\right) \quad \Longrightarrow \quad F\left(x_{1}, y\right)<F\left(x_{2}, y\right), \\
y_{1}, y_{2} \in X, & g\left(y_{1}\right)<g\left(y_{2}\right) \quad \Longrightarrow \quad F\left(x, y_{1}\right)>F\left(x, y_{2}\right) .
\end{array}
$$

Since we shall be dealing with coupled best proximity points, the following definitions will be needed.

Definition 1.3 Let $A, B$ be nonempty subsets of a metric space $(X, d)$, and $T: A \rightarrow B$ be a non-self mapping. A point $x^{*} \in A$ is called a best proximity point of $T$ if $d\left(x^{*}, T\left(x^{*}\right)\right)=$ $d(A, B)$, where

$$
d(A, B):=\inf \{d(x, y): x \in A, y \in B\}
$$

In this paper we shall use the following symbols:

$$
\begin{aligned}
& A_{0}=\{x \in A: d(x, y)=d(A, B) \text { for some } y \in B\}, \\
& B_{0}=\{y \in B: d(x, y)=d(A, B) \text { for some } x \in A\} .
\end{aligned}
$$

It is well known that $A_{0}$ is contained in the boundary of $A$ (see, for instance, [15]). For more information on some recent results in this topic, we refer the interested reader to [16-20]. In [21], the authors defined the notion of a coupled best proximity point, as follows.

Definition 1.4 Let $A, B$ be nonempty subsets of a metric space $(X, d)$ and $F: A \times A \rightarrow B$ be a mapping. A point $\left(x_{1}, x_{2}\right) \in A \times A$ is called a coupled best proximity point of $F$ if

$$
d\left(x_{1}, F\left(x_{1}, x_{2}\right)\right)=d\left(x_{2}, F\left(x_{2}, x_{1}\right)\right)=d(A, B) .
$$


It is easy to see that if $A=B$ in Definition 1.4 , then a coupled best proximity point is a coupled fixed point of $F$.

Pragadeeswarar et al. [22] defined a proximally coupled contraction as follows.

Definition 1.5 Let $(X, d, \leq)$ be a partially ordered metric space and $A, B$ be nonempty subsets of $X$. A mapping $F: A \times A \rightarrow B$ is said to be a proximally coupled contraction if there exists $k \in(0,1)$ such that whenever

$$
\left\{\begin{array}{l}
x_{1} \leq x_{2}, \quad y_{1} \geq y_{2}, \\
d\left(u_{1}, F\left(x_{1}, y_{1}\right)\right)=d(A, B), \\
d\left(u_{2}, F\left(x_{2}, y_{2}\right)\right)=d(A, B)
\end{array}\right.
$$

it follows that

$$
d\left(u_{1}, u_{2}\right) \leq \frac{k}{2}\left[d\left(x_{1}, x_{2}\right)+d\left(y_{1}, y_{2}\right)\right]
$$

where $x_{1}, x_{2}, y_{1}, y_{2}, u_{1}, u_{2} \in A$.

Motivated by the results of [14] and [22], in this paper we first introduce the notions of proximal mixed strict monotone property and proximally Meir-Keeler type functions and prove the existence and uniqueness of coupled best proximity point theorems for these mappings. This will be implemented in Section 2. In Section 3, we shall discuss some more generalizations of this notions. An example will be provided to illustrate our result.

\section{Proximally Meir-Keeler type mappings}

In this section we will define proximal mixed strict monotone property and proximally Meir-Keeler type mappings, and prove some theorems in this regard. In the next section we deal with some further generalizations of this topics. Therefore, we shall not provide any proof for the statements made in this section, instead we will comment on how these facts can be inferred from their counterparts in Section 3; indeed, the next section is devoted to proximally g-Meir-Keeler type mappings, as well as to proximal mixed strict g-monotone property, so that if we put $g$ = identity, we get all the results stated in Section 2.

Definition 2.1 Let $(X, d, \leq)$ be a partially ordered metric space, $A, B$ be nonempty subsets of $X$, and $F: A \times A \rightarrow B$ be a given mapping. We say that $F$ has the proximal mixed strict monotone property if, for all $x, y \in A$,

$$
\left\{\begin{array}{l}
x_{1}<x_{2}, \\
d\left(u_{1}, F\left(x_{1}, y\right)\right)=d(A, B), \\
d\left(u_{2}, F\left(x_{2}, y\right)\right)=d(A, B),
\end{array}\right.
$$

then $u_{1}<u_{2}$ and if

$$
\left\{\begin{array}{l}
y_{1} \leq y_{2}, \\
d\left(u_{3}, F\left(x, y_{1}\right)\right)=d(A, B), \\
d\left(u_{4}, F\left(x, y_{2}\right)\right)=d(A, B),
\end{array}\right.
$$

then $u_{4} \leq u_{3}$, where $x_{1}, x_{2}, y_{1}, y_{2}, u_{1}, u_{2}, u_{3}, u_{4} \in A$. 
Definition 2.2 Let $(X, d, \leq)$ be a partially ordered metric space, $A, B$ be nonempty subsets of $X$, and $F: A \times A \rightarrow B$ be a given mapping. We say that $F$ is a proximally Meir-Keeler type function if, for every $\epsilon>0$, there exist $\delta(\epsilon)>0$ and $k \in(0,1)$ such that whenever

$$
\left\{\begin{array}{l}
x_{1} \leq x_{2}, \quad y_{1} \geq y_{2} \\
d\left(u_{1}, F\left(x_{1}, y_{1}\right)\right)=d(A, B) \\
d\left(u_{2}, F\left(x_{2}, y_{2}\right)\right)=d(A, B)
\end{array}\right.
$$

then

$$
\epsilon \leq \frac{k}{2}\left[d\left(x_{1}, x_{2}\right)+d\left(y_{1}, y_{2}\right)\right]<\epsilon+\delta(\epsilon) \quad \Longrightarrow \quad d\left(u_{1}, u_{2}\right)<\epsilon,
$$

where $x_{1}, x_{2}, y_{1}, y_{2}, u_{1}, u_{2} \in A$.

Proposition 2.3 Let $(X, d, \leq)$ be a partially ordered metric space, $A, B$ be nonempty subsets of $X$, and let $F: A \times A \rightarrow B$ be a given mapping such that the conditions

$$
\left\{\begin{array}{l}
x_{1} \leq x_{2}, \quad y_{1} \geq y_{2}, \\
d\left(u_{1}, F\left(x_{1}, y_{1}\right)\right)=d(A, B), \\
d\left(u_{2}, F\left(x_{2}, y_{2}\right)\right)=d(A, B)
\end{array}\right.
$$

imply

$$
\exists k \in(0,1) ; \quad d\left(u_{1}, u_{2}\right) \leq \frac{k}{2}\left[d\left(x_{1}, x_{2}\right)+d\left(y_{1}, y_{2}\right)\right],
$$

where $x_{1}, x_{2}, y_{1}, y_{2}, u_{1}, u_{2} \in A$. Then $F$ is a proximally Meir-Keeler type function.

From now on, we suppose that $(X, d, \leq)$ is a partially ordered metric space endowed with the following partial ordering: for all $(x, y),(u, v) \in X \times X$,

$$
(u, v) \leq(x, y) \quad \Longleftrightarrow u<x, \quad v \geq y .
$$

Lemma 2.4 Let $(X, d, \leq)$ be a partially ordered metric space, $A, B$ be nonempty subsets of $X$, and let $F: A \times A \rightarrow B$ be a given mapping. If $F$ is a proximally Meir-Keeler type function, and

$$
\left\{\begin{array}{l}
\left(x_{1}, y_{1}\right) \leq\left(x_{2}, y_{2}\right) \\
d\left(u_{1}, F\left(x_{1}, y_{1}\right)\right)=d(A, B) \\
d\left(u_{2}, F\left(x_{2}, y_{2}\right)\right)=d(A, B)
\end{array}\right.
$$

then

$$
\exists k \in(0,1) ; \quad d\left(u_{1}, u_{2}\right) \leq \frac{k}{2}\left[d\left(x_{1}, x_{2}\right)+d\left(y_{1}, y_{2}\right)\right],
$$

where $x_{1}, x_{2}, y_{1}, y_{2}, u_{1}, u_{2} \in A$.

Theorem 2.5 Let $(X, d, \leq)$ be a partially ordered complete metric space. Let $A, B$ be nonempty closed subsets of the metric space $(X, d)$ such that $A_{0} \neq \emptyset$. Let $F: A \times A \rightarrow B$ 
be a given mapping satisfying the following conditions:

(a) $F$ is continuous;

(b) $F$ has the proximal mixed strict monotone property on $A$ such that $F\left(A_{0}, A_{0}\right) \subseteq B_{0}$;

(c) $F$ is a proximally Meir-Keeler type function;

(d) there exist elements $\left(x_{0}, y_{0}\right),\left(x_{1}, y_{1}\right) \in A_{0} \times A_{0}$ such that $d\left(x_{1}, F\left(x_{0}, y_{0}\right)\right)=d(A, B)$ with $x_{0}<x_{1}$, and $d\left(y_{1}, F\left(y_{0}, x_{0}\right)\right)=d(A, B)$ with $y_{0} \geq y_{1}$.

Then there exists $(x, y) \in A \times A$ such that $d(x, F(x, y))=d(A, B)$ and $d(y, F(y, x))=d(A, B)$.

Theorem 2.6 Let $(X, d, \leq)$ be a partially ordered complete metric space. Let $A$ be a nonempty closed subset of the metric space $(X, d)$. Let $F: A \times A \rightarrow A$ be a given mapping satisfying the following conditions:

(a) $F$ is continuous;

(b) $F$ has the proximal mixed strict monotone property on $A$;

(c) $F$ is a proximally Meir-Keeler type function;

(d) there exist elements $\left(x_{0}, y_{0}\right),\left(x_{1}, y_{1}\right) \in A \times A$ such that $x_{1}=F\left(x_{0}, y_{0}\right)$ with $x_{0}<x_{1}$, and $y_{1}=F\left(y_{0}, x_{0}\right)$ with $y_{0} \geq y_{1}$.

Then there exists $(x, y) \in A \times A$ such that $d(x, F(x, y))=0$ and $d(y, F(y, x))=0$.

Theorem 2.7 Let $(X, d, \leq)$ be a partially ordered complete metric space. Let $A, B$ be nonempty closed subsets of the metric space $(X, d)$ such that $A_{0} \neq \emptyset$. Let $F: A \times A \rightarrow B$ be a given mapping satisfying the following conditions:

(a) if $\left\{x_{n}\right\}$ is a nondecreasing sequence in $A$ such that such that $x_{n} \rightarrow x$, then $x_{n}<x$ and if $\left\{y_{n}\right\}$ is a nonincreasing sequence in $A$ such that $y_{n} \rightarrow y$, then $y_{n} \geq y$;

(b) $F$ has the proximal mixed strict monotone property on $A$ such that $F\left(A_{0}, A_{0}\right) \subseteq B_{0}$;

(c) $F$ is a proximally Meir-Keeler type function;

(d) there exist elements $\left(x_{0}, y_{0}\right),\left(x_{1}, y_{1}\right) \in A_{0} \times A_{0}$ such that $d\left(x_{1}, F\left(x_{0}, y_{0}\right)\right)=d(A, B)$ with $x_{0}<x_{1}$, and $d\left(y_{1}, F\left(y_{0}, x_{0}\right)\right)=d(A, B)$ with $y_{0} \geq y_{1}$.

Then there exists $(x, y) \in A \times A$ such that $d(x, F(x, y))=d(A, B)$ and $d(y, F(y, x))=d(A, B)$.

Remark 2.8 Theorems 2.5 and 2.6 hold true, if we replace the continuity of $F$ by the following.

If $\left\{x_{n}\right\}$ is a nondecreasing sequence in $A$ such that $x_{n} \rightarrow x$, then $x_{n}<x$ and if $\left\{y_{n}\right\}$ is a nonincreasing sequence in $A$ such that $y_{n} \rightarrow y$, then $y_{n} \geq y$.

Now, we consider the product space $A \times A$ with the following partial ordering: for all $(x, y),(u, v) \in A \times A$,

$$
(u, v) \leq(x, y) \quad \Longleftrightarrow u<x, \quad v \geq y .
$$

Theorem 2.9 Suppose that all the hypotheses of Theorem 2.5 hold and, further, for all $(x, y),\left(x^{*}, y^{*}\right) \in A_{0} \times A_{0}$, there exists $(u, v) \in A_{0} \times A_{0}$ such that $(u, v)$ is comparable with $(x, y),\left(x^{*}, y^{*}\right)$. Then there exists a unique $(x, y) \in A \times A$ such that $d(x, F(x, y))=d(A, B)$ and $d(y, F(y, x))=d(A, B)$.

Example 2.10 Let $X$ be the real numbers endowed with usual metric and consider the usual ordering $(x, y) \leq(u, v) \Longleftrightarrow x \leq u, y \leq v$. Suppose that $A=[3,+\infty)$ and $B=(-\infty,-3]$. 
Then $A, B$ are nonempty closed subsets of $X$. Also, we have $d(A, B)=6, A_{0}=\{3\}$ and $B_{0}=\{-3\}$. Define a mapping $F: A \times A \rightarrow B$ as follows:

$$
F(x, y)=\frac{-x-y}{2} .
$$

Then $F$ is continuous and $F(3,3)=-3$, i.e., $F\left(A_{0}, A_{0}\right) \subseteq B_{0}$.

Note also that the other hypotheses of Theorem 2.9 are satisfied, then there exists a unique point $(3,3) \in A \times A$ such that $d(3, F(3,3))=6=d(A, B)$.

\section{Proximally $g$-Meir-Keeler type mappings}

Let $X$ be a nonempty set. We recall that an element $(x, y) \in X \times X$ is called a coupled coincidence point of two mappings $F: X \times X \rightarrow X$ and $g: X \rightarrow X$ provided that $F(x, y)=g(x)$ and $F(y, x)=g(y)$ for all $x, y \in X$. Also, we say that $F$ and $g$ are commutative if $g(F(x, y))=F(g(x), g(y))$ for all $x, y \in X$.

We now present the following definitions.

Definition 3.1 Let $(X, d, \leq)$ be a partially ordered metric space, $A, B$ be nonempty subsets of $X$, and $F: A \times A \rightarrow B$ and $g: A \rightarrow A$ be two given mappings. We say that $F$ has the proximal mixed strict $g$-monotone property provided that for all $x, y \in A$, if

$$
\left\{\begin{array}{l}
g\left(x_{1}\right)<g\left(x_{2}\right), \\
d\left(g\left(u_{1}\right), F\left(g\left(x_{1}\right), g(y)\right)\right)=d(A, B), \\
d\left(g\left(u_{2}\right), F\left(g\left(x_{2}\right), g(y)\right)\right)=d(A, B),
\end{array}\right.
$$

then $g\left(u_{1}\right)<g\left(u_{2}\right)$, and if

$$
\left\{\begin{array}{l}
g\left(y_{1}\right) \leq g\left(y_{2}\right), \\
d\left(g\left(u_{3}\right), F\left(g(x), g\left(y_{1}\right)\right)\right)=d(A, B), \\
d\left(g\left(u_{4}\right), F\left(g(x), g\left(y_{2}\right)\right)\right)=d(A, B),
\end{array}\right.
$$

then $g\left(u_{4}\right) \leq g\left(u_{3}\right)$, where $x_{1}, x_{2}, y_{1}, y_{2}, u_{1}, u_{2}, u_{3}, u_{4} \in A$.

Definition 3.2 Let $(X, d, \leq)$ be a partially ordered metric space, $A, B$ be nonempty subsets of $X$, and $F: A \times A \rightarrow B$ and $g: A \rightarrow A$ be two given mappings. We say that $F$ is a proximally $g$-Meir-Keeler type function if, for every $\epsilon>0$, there exist $\delta(\epsilon)>0$ and $k \in(0,1)$ such that whenever

$$
\left\{\begin{array}{l}
g\left(x_{1}\right) \leq g\left(x_{2}\right), \quad g\left(y_{1}\right) \geq g\left(y_{2}\right), \\
d\left(g\left(u_{1}\right), F\left(g\left(x_{1}\right), g\left(y_{1}\right)\right)\right)=d(A, B), \\
d\left(g\left(u_{2}\right), F\left(g\left(x_{2}\right), g\left(y_{2}\right)\right)\right)=d(A, B),
\end{array}\right.
$$

then

$$
\epsilon \leq \frac{k}{2}\left[d\left(g\left(x_{1}\right), g\left(x_{2}\right)\right)+d\left(g\left(y_{1}\right), g\left(y_{2}\right)\right)\right]<\epsilon+\delta(\epsilon) \quad \Longrightarrow \quad d\left(g\left(u_{1}\right), g\left(u_{2}\right)\right)<\epsilon,
$$

where $x_{1}, x_{2}, y_{1}, y_{2}, u_{1}, u_{2} \in A$.

Proposition 3.3 Let $(X, d, \leq)$ be a partially ordered metric space and $A, B$ be nonempty subsets of $X$, and let $F: A \times A \rightarrow B$ and $g: A \rightarrow A$ be two given mappings such that the 
conditions

$$
\left\{\begin{array}{l}
g\left(x_{1}\right) \leq g\left(x_{2}\right), \quad g\left(y_{1}\right) \geq g\left(y_{2}\right), \\
d\left(g\left(u_{1}\right), F\left(g\left(x_{1}\right), g\left(y_{1}\right)\right)\right)=d(A, B), \\
d\left(g\left(u_{2}\right), F\left(g\left(x_{2}\right), g\left(y_{2}\right)\right)\right)=d(A, B),
\end{array}\right.
$$

imply

$$
\exists k \in(0,1) ; \quad d\left(g\left(u_{1}\right), g\left(u_{2}\right)\right) \leq \frac{k}{2}\left[d\left(g\left(x_{1}\right), g\left(x_{2}\right)\right)+d\left(g\left(y_{1}\right), g\left(y_{2}\right)\right)\right],
$$

where $x_{1}, x_{2}, y_{1}, y_{2}, u_{1}, u_{2} \in A$. Then $F$ is a proximally g-Meir-Keeler type function.

Proof Suppose (1) is satisfied. For every $\epsilon>0$, we set $\epsilon_{0}=\epsilon / 2$ and $\delta\left(\epsilon_{0}\right)=\epsilon_{0}$. Now, if $\epsilon_{0} \leq \frac{k}{2}\left[d\left(g\left(x_{1}\right), g\left(x_{2}\right)\right)+d\left(g\left(y_{1}\right), g\left(y_{2}\right)\right)\right]<\epsilon+\delta(\epsilon)$, it follows from (1) that $d\left(g\left(u_{1}\right), g\left(u_{2}\right)\right) \leq$ $\frac{k}{2}\left[d\left(g\left(x_{1}\right), g\left(x_{2}\right)\right)+d\left(g\left(y_{1}\right), g\left(y_{2}\right)\right)\right]<\epsilon_{0}+\delta\left(\epsilon_{0}\right)=\epsilon$, i.e., $d\left(g\left(u_{1}\right), g\left(u_{2}\right)\right)<\epsilon$.

Remark 3.4 If we set $g=I$, the identity map, in Proposition 3.3, then Proposition 2.3 follows.

From now on, we suppose that $(X, d, \leq)$ is a partially ordered metric space endowed with the following partial ordering: for all $(x, y),(u, v) \in X \times X$,

$$
(u, v) \leq(x, y) \quad \Longleftrightarrow u<x, \quad v \geq y .
$$

Lemma 3.5 Let $(X, d, \leq)$ be a partially ordered metric space and $A, B$ be nonempty subsets of $X$ and let $F: A \times A \rightarrow B$ and $g: A \rightarrow A$ be two given mappings. If $F$ is a proximally $g$-Meir-Keeler type function, and

$$
\left\{\begin{array}{l}
\left(g\left(x_{1}\right), g\left(y_{1}\right)\right) \leq\left(g\left(x_{2}\right), g\left(y_{2}\right)\right), \\
d\left(g\left(u_{1}\right), F\left(g\left(x_{1}\right), g\left(y_{1}\right)\right)\right)=d(A, B), \\
d\left(g\left(u_{2}\right), F\left(g\left(x_{2}\right), g\left(y_{2}\right)\right)\right)=d(A, B),
\end{array}\right.
$$

then

$$
\exists k \in(0,1) ; \quad d\left(g\left(u_{1}\right), g\left(u_{2}\right)\right) \leq \frac{k}{2}\left[d\left(g\left(x_{1}\right), g\left(x_{2}\right)\right)+d\left(g\left(y_{1}\right), g\left(y_{2}\right)\right)\right],
$$

where $x_{1}, x_{2}, y_{1}, y_{2}, u_{1}, u_{2} \in A$.

Proof Let $x_{1}, x_{2}, y_{1}, y_{2} \in A$ be such that

$$
\left\{\begin{array}{l}
\left(g\left(x_{1}\right), g\left(y_{1}\right)\right) \leq\left(g\left(x_{2}\right), g\left(y_{2}\right)\right), \\
d\left(g\left(u_{1}\right), F\left(g\left(x_{1}\right), g\left(y_{1}\right)\right)\right)=d(A, B), \\
d\left(g\left(u_{2}\right), F\left(g\left(x_{2}\right), g\left(y_{2}\right)\right)\right)=d(A, B),
\end{array}\right.
$$

then $d\left(g\left(x_{1}\right), g\left(x_{2}\right)\right)+d\left(g\left(y_{1}\right), g\left(y_{2}\right)\right)>0$.

Let $k_{0} \in(0,1)$ be arbitrary. Since $F$ is a proximally $g$-Meir-Keeler type function, for

$$
\epsilon=\frac{k_{0}}{2}\left[d\left(g\left(x_{1}\right), g\left(x_{2}\right)\right)+d\left(g\left(y_{1}\right), g\left(y_{2}\right)\right)\right]
$$


there exist $\delta(\epsilon)>0$ and $k=k_{0} \in(0,1)$ such that for all $x_{1}, x_{2}, y_{1}, y_{2}, u_{1}, u_{2} \in A$ for which $\left(g\left(x_{1}\right), g\left(y_{1}\right)\right) \leq\left(g\left(x_{2}\right), g\left(y_{2}\right)\right)$, and

$$
\left\{\begin{array}{l}
d\left(g\left(u_{1}\right), F\left(g\left(x_{1}\right), g\left(y_{1}\right)\right)\right)=d(A, B), \\
d\left(g\left(u_{2}\right), F\left(g\left(x_{2}\right), g\left(y_{2}\right)\right)\right)=d(A, B),
\end{array}\right.
$$

we have

$$
\epsilon \leq \frac{k}{2}\left[d\left(g\left(x_{1}\right), g\left(x_{2}\right)\right)+d\left(g\left(y_{1}\right), g\left(y_{2}\right)\right)\right]<\epsilon+\delta(\epsilon) \quad \Longrightarrow \quad d\left(g\left(u_{1}\right), g\left(u_{2}\right)\right)<\epsilon,
$$

therefore,

$$
\begin{aligned}
d\left(g\left(u_{1}\right), g\left(u_{2}\right)\right) & <\frac{k_{0}}{2}\left[d\left(g\left(x_{1}\right), g\left(x_{2}\right)\right)+d\left(g\left(y_{1}\right), g\left(y_{2}\right)\right)\right] \\
& =\frac{k}{2}\left[d\left(g\left(x_{1}\right), g\left(x_{2}\right)\right)+d\left(g\left(y_{1}\right), g\left(y_{2}\right)\right)\right] .
\end{aligned}
$$

This completes the proof.

Remark 3.6 If in Lemma 3.5, we set $g=I$ the identity map, Lemma 2.4 follows.

Lemma 3.7 Let $(X, d, \leq)$ be a partially ordered metric space and $A, B$ be nonempty subsets of $X, A_{0} \neq \emptyset$ and $F: A \times A \rightarrow B$ and $g: A \rightarrow A$ be two given mappings. If $F$ has the proximal mixed strict $g$-monotone property, with $g\left(A_{0}\right)=A_{0}, F\left(A_{0}, A_{0}\right) \subseteq B_{0}$, and if $\left(g\left(x_{1}\right), g\left(y_{1}\right)\right) \leq$ $\left(g\left(x_{2}\right), g\left(y_{2}\right)\right)$,

$$
\begin{aligned}
& d\left(g\left(x_{2}\right), F\left(g\left(x_{1}\right), g\left(y_{1}\right)\right)\right)=d(A, B), \\
& d\left(g(u), F\left(g\left(x_{2}\right), g\left(y_{2}\right)\right)\right)=d(A, B),
\end{aligned}
$$

where $x_{1}, x_{2}, y_{1}, y_{2}, u \in A_{0}$, then $g\left(x_{2}\right)<g(u)$.

Proof Since $g\left(A_{0}\right)=A_{0}, F\left(A_{0}, A_{0}\right) \subseteq B_{0}$, it follows that $F\left(g\left(x_{2}\right), g\left(y_{1}\right)\right) \in B_{0}$. Hence there exists $g\left(u_{1}^{*}\right) \in A_{0}$ such that

$$
d\left(g\left(u_{1}^{*}\right), F\left(g\left(x_{2}\right), g\left(y_{1}\right)\right)\right)=d(A, B) .
$$

Using the fact that $F$ has the proximal mixed strict $g$-monotone property, together with (2) and (4), we have

$$
\left\{\begin{array}{l}
g\left(x_{1}\right)<g\left(x_{2}\right), \\
d\left(g\left(x_{2}\right), F\left(g\left(x_{1}\right), g\left(y_{1}\right)\right)\right)=d(A, B), \\
d\left(g\left(u_{1}^{*}\right), F\left(g\left(x_{2}\right), g\left(y_{1}\right)\right)\right)=d(A, B),
\end{array}\right.
$$

then

$$
g\left(x_{2}\right)<g\left(u_{1}^{*}\right) .
$$


Also, from the proximal mixed strict $g$-monotone property of $F$ with (3), (5), we have

$$
\left\{\begin{array}{l}
g\left(y_{2}\right) \leq g\left(y_{1}\right), \\
d\left(g(u), F\left(g\left(x_{2}\right), g\left(y_{2}\right)\right)\right)=d(A, B), \\
d\left(g\left(u_{1}^{*}\right), F\left(g\left(x_{2}\right), g\left(y_{1}\right)\right)\right)=d(A, B),
\end{array}\right.
$$

then

$$
g\left(u_{1}^{*}\right) \leq g(u)
$$

Now from (5), (6) we get $g\left(x_{2}\right)<g(u)$, hence the proof is complete.

Lemma 3.8 Let $(X, d, \leq)$ be a partially ordered metric space and $A, B$ be nonempty subsets of $X, A_{0} \neq \emptyset$, and $F: A \times A \rightarrow B$ and $g: A \rightarrow A$ be two given mappings. Let $F$ have the proximal mixed strict $g$-monotone property, with $g\left(A_{0}\right)=A_{0}, F\left(A_{0}, A_{0}\right) \subseteq B_{0}$. If

$$
\left\{\begin{array}{l}
\left(g\left(x_{1}\right), g\left(y_{1}\right)\right) \leq\left(g\left(x_{2}\right), g\left(y_{2}\right)\right), \\
d\left(g\left(y_{2}\right), F\left(g\left(y_{1}\right), g\left(x_{1}\right)\right)\right)=d(A, B), \\
d\left(g(u), F\left(g\left(y_{2}\right), g\left(x_{2}\right)\right)\right)=d(A, B)
\end{array}\right.
$$

where $x_{1}, x_{2}, y_{1}, y_{2}, u \in A_{0}$, then $g\left(y_{2}\right)>g(u)$.

Proof The proof is similar to that of Lemma 3.7, so we omit the details.

Theorem 3.9 Let $(X, d, \leq)$ be a partially ordered complete metric space. Let $A, B$ be nonempty closed subsets of the metric space $(X, d)$ such that $A_{0} \neq \emptyset$. Let $F: A \times A \rightarrow B$ and $g: A \rightarrow A$ be two given mappings satisfying the following conditions:

(a) $F$ and $g$ are continuous;

(b) $F$ has the proximal mixed strict $g$-monotone property on $A$ such that $g\left(A_{0}\right)=A_{0}$,

$$
F\left(A_{0}, A_{0}\right) \subseteq B_{0}
$$

(c) $F$ is a proximally $g$-Meir-Keeler type function;

(d) there exist elements $\left(x_{0}, y_{0}\right),\left(x_{1}, y_{1}\right) \in A_{0} \times A_{0}$ such that $d\left(g\left(x_{1}\right), F\left(g\left(x_{0}\right), g\left(y_{0}\right)\right)\right)=d(A, B)$ with $g\left(x_{0}\right)<g\left(x_{1}\right)$, and $d\left(g\left(y_{1}\right), F\left(g\left(y_{0}\right), g\left(x_{0}\right)\right)\right)=d(A, B)$ with $g\left(y_{0}\right) \geq g\left(y_{1}\right)$.

Then there exists $(x, y) \in A \times A$ such that $d(g(x), F(g(x), g(y)))=d(A, B)$ and $d(g(y), F(g(y)$, $g(x)))=d(A, B)$.

Proof Let $\left(x_{0}, y_{0}\right),\left(x_{1}, y_{1}\right) \in A_{0} \times A_{0}$ be such that $d\left(g\left(x_{1}\right), F\left(g\left(x_{0}\right), g\left(y_{0}\right)\right)\right)=d(A, B)$ with $g\left(x_{0}\right)<g\left(x_{1}\right)$, and $d\left(g\left(y_{1}\right), F\left(g\left(y_{0}\right), g\left(x_{0}\right)\right)\right)=d(A, B)$ with $g\left(y_{0}\right) \geq g\left(y_{1}\right)$.

Since $F\left(A_{0}, A_{0}\right) \subseteq B_{0}, g\left(A_{0}\right)=A_{0}$, there exists an element $\left(x_{2}, y_{2}\right) \in A_{0} \times A_{0}$ such that $d\left(g\left(x_{2}\right), F\left(g\left(x_{1}\right), g\left(y_{1}\right)\right)\right)=d(A, B)$ and $d\left(g\left(y_{2}\right), F\left(g\left(y_{1}\right), g\left(x_{1}\right)\right)\right)=d(A, B)$.

Hence from Lemma 3.7 and Lemma 3.8 we obtain $g\left(x_{1}\right)<g\left(x_{2}\right)$ and $g\left(y_{1}\right)>g\left(y_{2}\right)$.

Continuing this process, we construct the sequences $\left\{x_{n}\right\}$ and $\left\{y_{n}\right\}$ in $A_{0}$ such that

$$
d\left(g\left(x_{n+1}\right), F\left(g\left(x_{n}\right), g\left(y_{n}\right)\right)\right)=d(A, B), \quad \forall n \geq 0,
$$

with

$$
g\left(x_{0}\right)<g\left(x_{1}\right)<\cdots<g\left(x_{n}\right)<g\left(x_{n+1}\right)<\cdots
$$


and

$$
d\left(g\left(y_{n+1}\right), F\left(g\left(y_{n}\right), g\left(x_{n}\right)\right)\right)=d(A, B), \quad \forall n \geq 0,
$$

with

$$
g\left(y_{0}\right)>g\left(y_{1}\right)>\cdots>g\left(y_{n}\right)>g\left(y_{n+1}\right)>\cdots .
$$

Define

$$
\delta_{n}:=d\left(g\left(x_{n}\right), g\left(x_{n+1}\right)\right)+d\left(g\left(y_{n}\right), g\left(y_{n+1}\right)\right) .
$$

Since $F$ is a proximally $g$-Meir-Keeler type function, $d\left(g\left(x_{n}\right), F\left(g\left(x_{n-1}\right), g\left(y_{n-1}\right)\right)\right)=d(A, B)$, and

$$
d\left(g\left(x_{n+1}\right), F\left(g\left(x_{n}\right), g\left(y_{n}\right)\right)\right)=d(A, B), \quad g\left(x_{n-1}\right) \leq g\left(x_{n}\right), g\left(y_{n-1}\right) \geq g\left(y_{n}\right),
$$

it follows from Lemma 3.5 that

$$
d\left(g\left(x_{n}\right), g\left(x_{n+1}\right)\right) \leq \frac{k}{2}\left[d\left(g\left(x_{n-1}\right), g\left(x_{n}\right)\right)+d\left(g\left(y_{n-1}\right), g\left(y_{n}\right)\right)\right] .
$$

We also have $d\left(g\left(y_{n}\right), F\left(g\left(y_{n-1}\right), g\left(x_{n-1}\right)\right)\right)=d(A, B)$, and

$$
d\left(g\left(y_{n+1}\right), F\left(g\left(y_{n}\right), g\left(x_{n}\right)\right)\right)=d(A, B), \quad g\left(x_{n-1}\right)<g\left(x_{n}\right), g\left(y_{n-1}\right)>g\left(y_{n}\right),
$$

hence using the fact that $F$ is a proximally $g$-Meir-Keeler type function, it follows from Lemma 3.5 that

$$
d\left(g\left(y_{n}\right), g\left(y_{n+1}\right)\right) \leq \frac{k}{2}\left[d\left(g\left(y_{n-1}\right), g\left(y_{n}\right)\right)+d\left(g\left(x_{n-1}\right), g\left(x_{n}\right)\right)\right] .
$$

It now follows from (9), (10), and (11) that

$$
\delta_{n} \leq k\left(\delta_{n-1}\right) \leq k^{2}\left(\delta_{n-2}\right) \leq \cdots \leq k^{n}\left(\delta_{0}\right)
$$

or

$$
\delta_{n} \leq k^{n}\left(\delta_{0}\right)
$$

Now, we prove that $\left\{g\left(x_{n}\right)\right\}$ and $\left\{g\left(y_{n}\right)\right\}$ are Cauchy sequences. For $n>m$, it follows from the triangle inequality and (12) that

$$
\begin{aligned}
& d\left(g\left(x_{n}\right), g\left(x_{m}\right)\right)+d\left(g\left(y_{n}\right), g\left(y_{m}\right)\right) \\
& \quad \leq d\left(g\left(x_{n}\right), g\left(x_{n-1}\right)\right)+d\left(g\left(y_{n}\right), g\left(y_{n-1}\right)\right)+\cdots+d\left(g\left(x_{m+1}\right), g\left(x_{m}\right)\right)+d\left(g\left(y_{m+1}\right), g\left(y_{m}\right)\right) \\
& \quad \leq\left(k^{n-1}+\cdots+k^{m}\right)\left(\delta_{0}\right) \\
& \quad \leq \frac{k^{m}}{1-k}\left(\delta_{0}\right) .
\end{aligned}
$$


Let $\epsilon>0$ be given. Choose a natural number $N$ such that $\frac{k^{m}}{1-k}\left(\delta_{0}\right)<\epsilon$, for $m>N$. Thus,

$$
d\left(g\left(x_{n}\right), g\left(x_{m}\right)\right)+d\left(g\left(y_{n}\right), g\left(y_{m}\right)\right)<\epsilon, \quad n>m .
$$

Therefore, $\left\{g\left(x_{n}\right)\right\}$ and $\left\{g\left(y_{n}\right)\right\}$ are Cauchy sequences.

Since $A$ is a closed subset of the complete metric space $X$, there exist $x^{1}, y^{1} \in A$ such that

$$
\lim _{n \rightarrow \infty} g\left(x_{n}\right)=x^{1}, \quad \lim _{n \rightarrow \infty} g\left(y_{n}\right)=y^{1} .
$$

Note that $x_{n}, y_{n} \in A_{0}, g\left(A_{0}\right)=A_{0}$, so that $g\left(x_{n}\right), g\left(y_{n}\right) \in A_{0}$. Since $A_{0}$ is closed, we conclude that $\left(x^{1}, y^{1}\right) \in A_{0} \times A_{0}$, i.e., there exist $x, y \in A_{0}$ such that $g(x)=x^{1}, g(y)=y^{1}$. Therefore

$$
g\left(x_{n}\right) \rightarrow g(x), \quad g\left(y_{n}\right) \rightarrow g(y)
$$

Since $\left\{g\left(x_{n}\right)\right\}$ is monotone increasing and $\left\{g\left(y_{n}\right)\right\}$ is monotone decreasing, we have

$$
g\left(x_{n}\right)<g(x), \quad g\left(y_{n}\right)>g(y) .
$$

From (7), (8),

$$
d\left(g\left(x_{n+1}\right), F\left(g\left(x_{n}\right), g\left(y_{n}\right)\right)\right)=d(A, B)
$$

and

$$
d\left(g\left(y_{n+1}\right), F\left(g\left(y_{n}\right), g\left(x_{n}\right)\right)\right)=d(A, B) .
$$

Since $F$ is continuous, we have, from (13),

$$
F\left(g\left(x_{n}\right), g\left(y_{n}\right)\right) \rightarrow F(g(x), g(y))
$$

and

$$
F\left(g\left(y_{n}\right), g\left(x_{n}\right)\right) \rightarrow F(g(y), g(x)) .
$$

Thus, the continuity of the metric $d$ implies that

$$
d\left(g\left(x_{n+1}\right), F\left(g\left(x_{n}\right), g\left(y_{n}\right)\right)\right) \rightarrow d(g(x), F(g(x), g(y)))
$$

and

$$
d\left(g\left(y_{n+1}\right), F\left(g\left(y_{n}\right), g\left(x_{n}\right)\right)\right) \rightarrow d(g(y), F(g(y), g(x))) .
$$

Therefore from (15), (16), (17), (18),

$$
d(g(x), F(g(x), g(y)))=d(A, B), \quad d(g(y), F(g(y), g(x)))=d(A, B) .
$$

Remark 3.10 If we set $g=I$ in Theorem 3.9, Theorem 2.5 follows. 
Corollary 3.11 Let $(X, d, \leq)$ be a partially ordered complete metric space. Let $A$ be a nonempty closed subsets of the metric space $(X, d)$. Let $F: A \times A \rightarrow A$ and $g: A \rightarrow A$ be two given mappings satisfying the following conditions:

(a) F and $g$ are continuous;

(b) $F$ has the proximal mixed strict $g$-monotone property on $A$ such that

$F(g(A), g(A)) \subseteq g(A)$;

(c) $F$ is a proximally $g$-Meir-Keeler type function;

(d) there exist elements $\left(x_{0}, y_{0}\right),\left(x_{1}, y_{1}\right) \in A \times A$ such that $g\left(x_{1}\right)=F\left(g\left(x_{0}\right), g\left(y_{0}\right)\right)$ with $g\left(x_{0}\right)<g\left(x_{1}\right)$, and $g\left(y_{1}\right)=F\left(g\left(y_{0}\right), g\left(x_{0}\right)\right)$ with $g\left(y_{0}\right) \geq g\left(y_{1}\right)$.

Then there exists $(x, y) \in A \times A$ such that

$$
d(g(x), F(g(x), g(y)))=0, \quad d(g(y), F(g(y), g(x)))=0 .
$$

Theorem 3.12 Let $(X, d, \leq)$ be a partially ordered complete metric space. Let $A, B$ be nonempty closed subsets of the metric space $(X, d)$ such that $A_{0} \neq \emptyset$. Let $F: A \times A \rightarrow B$ and $g: A \rightarrow A$ be two given mappings satisfying the following conditions:

(a) $g$ is continuous;

(b) $F$ has the proximal mixed strict $g$-monotone property on $A$ such that $F\left(A_{0}, A_{0}\right) \subseteq B_{0}$, $g\left(A_{0}\right)=A_{0}$;

(c) $F$ is a proximally $g$-Meir-Keeler type function;

(d) there exist elements $\left(x_{0}, y_{0}\right),\left(x_{1}, y_{1}\right) \in A_{0} \times A_{0}$ such that $d\left(g\left(x_{1}\right), F\left(g\left(x_{0}\right), g\left(y_{0}\right)\right)\right)=d(A, B)$ with $g\left(x_{0}\right)<g\left(x_{1}\right)$, and $d\left(g\left(y_{1}\right), F\left(g\left(y_{0}\right), g\left(x_{0}\right)\right)\right)=d(A, B)$ with $g\left(y_{0}\right) \geq g\left(y_{1}\right)$;

(e) if $\left\{x_{n}\right\}$ is a nondecreasing sequence in $A$ such that $x_{n} \rightarrow x$, then $x_{n}<x$ and if $\left\{y_{n}\right\}$ is a nonincreasing sequence in $A$ such that $y_{n} \rightarrow y$, then $y_{n} \geq y$.

Then there exists $(x, y) \in A \times A$ such that

$$
d(g(x), F(g(x), g(y)))=d(A, B), \quad d(g(y), F(g(y), g(x)))=d(A, B) .
$$

Proof As in the proof of Theorem 3.9, there exist sequences $\left\{x_{n}\right\}$ and $\left\{y_{n}\right\}$ in $A_{0}$ such that $d\left(g\left(x_{n+1}\right), F\left(g\left(x_{n}\right), g\left(y_{n}\right)\right)\right)=d(A, B)$ with

$$
g\left(x_{n}\right)<g\left(x_{n+1}\right), \quad \forall n \geq 0,
$$

and $d\left(g\left(y_{n+1}\right), F\left(g\left(y_{n}\right), g\left(x_{n}\right)\right)\right)=d(A, B)$ with

$$
g\left(y_{n}\right)>g\left(y_{n+1}\right), \quad \forall n \geq 0 .
$$

Also, $g\left(x_{n}\right) \rightarrow g(x)$ and $g\left(y_{n}\right) \rightarrow g(y)$.

From (e), we get $g\left(x_{n}\right)<g(x)$, and $g\left(y_{n}\right) \geq g(y)$. Since $F\left(A_{0}, A_{0}\right) \subseteq B_{0}$, it follows that $F(g(x), g(y))$ and $F(g(y), g(x))$ are in $B_{0}$. Therefore, there exists $\left(x_{1}^{\star}, y_{1}^{\star}\right) \in A_{0} \times A_{0}$ such that $d\left(x_{1}^{\star}, F(g(x), g(y))\right)=d(A, B)$ and $d\left(y_{1}^{\star}, F(g(y), g(x))\right)=d(A, B)$.

Since $g\left(A_{0}\right)=A_{0}$, there exist $x^{*}, y^{*} \in A_{0}$ such that $g\left(x^{*}\right)=x_{1}^{*}, g\left(y^{*}\right)=y_{1}^{*}$. Hence,

$$
d\left(g\left(x^{\star}\right), F(g(x), g(y))\right)=d(A, B)
$$


and

$$
d\left(g\left(y^{\star}\right), F(g(y), g(x))\right)=d(A, B) .
$$

Since $g\left(x_{n}\right)<g(x), g\left(y_{n}\right) \geq g(y)$ and $F$ is a proximally $g$-Meir-Keeler type function, it follows from Lemma 3.5, (19), and (21) that

$$
d\left(g\left(x_{n+1}\right), g\left(x^{\star}\right)\right) \leq \frac{k}{2}\left[d\left(g\left(x_{n}\right), g(x)\right)+d\left(g\left(y_{n}\right), g(y)\right)\right]
$$

Similarly, from Lemma 3.5 and (20) and (22) we obtain

$$
d\left(g\left(y_{n+1}\right), g\left(y^{\star}\right)\right) \leq \frac{k}{2}\left[d\left(g\left(y_{n}\right), g(y)\right)+d\left(g\left(x_{n}\right), g(x)\right)\right]
$$

By taking the limit of the above two inequalities, we get $g(x)=g\left(x^{\star}\right)$ and $g(y)=g\left(y^{\star}\right)$.

Remark 3.13 Corollary 3.11 holds true if we replace the continuity of $F$ by the following statement.

If $\left\{x_{n}\right\}$ is a nondecreasing sequence in $A$ such that $x_{n} \rightarrow x$, then $x_{n}<x$ and if $\left\{y_{n}\right\}$ is a nonincreasing sequence in $A$ such that $y_{n} \rightarrow y$, then $y_{n} \geq y$.

We now consider the product space $A \times A$ with the following partial ordering: for all $(x, y),(u, v) \in A \times A$,

$$
(u, v) \leq(x, y) \Longleftrightarrow u<x, \quad v \geq y .
$$

Theorem 3.14 Suppose that all the hypotheses of Theorem 3.9 hold and, further, for all $(x, y),\left(x^{*}, y^{*}\right) \in A_{0} \times A_{0}$, there exists $(u, v) \in A_{0} \times A_{0}$ such that $(u, v)$ is comparable to $(x, y)$, $\left(x^{*}, y^{*}\right)$ (with respect to the ordering in $\left.A \times A\right)$. Then there exists a unique $(x, y) \in A \times A$ such that $d(g(x), F(g(x), g(y)))=d(A, B)$ and $d(g(y), F(g(y), g(x)))=d(A, B)$.

Proof By Theorem 3.9, there exists an element $(x, y) \in A \times A$ such that

$$
d(g(x), F(g(x), g(y)))=d(A, B)
$$

and

$$
d(g(y), F(g(y), g(x)))=d(A, B)
$$

Now, suppose that there exists an element $\left(x^{*}, y^{*}\right) \in A \times A$ such that $d\left(g\left(x^{*}\right), F\left(g\left(x^{*}\right), g\left(y^{*}\right)\right)\right)=$ $d(A, B)$ and $d\left(g\left(y^{*}\right), F\left(g\left(y^{*}\right), g\left(x^{*}\right)\right)\right)=d(A, B)$.

First, let $(g(x), g(y))$ be comparable to $\left(g\left(x^{*}\right), g\left(y^{*}\right)\right)$ with respect to the ordering in $A \times A$. Since $d(g(x), F(g(x), g(y)))=d(A, B)$, and $d\left(g\left(x^{*}\right), F\left(g\left(x^{*}\right), g\left(y^{*}\right)\right)\right)=d(A, B)$, it follows from Lemma 3.5 that

$$
\exists k \in(0,1) ; \quad d\left(g(x), g\left(x^{*}\right)\right) \leq \frac{k}{2}\left[d\left(g(x), g\left(x^{*}\right)\right)+d\left(g(y), g\left(y^{*}\right)\right)\right] .
$$


Similarly, from $d(g(y), F(g(y), g(x)))=d(A, B), d\left(g\left(y^{*}\right), F\left(g\left(y^{*}\right), g\left(x^{*}\right)\right)\right)=d(A, B)$ and Lemma 3.5, we have

$$
d\left(g(y), g\left(y^{*}\right)\right) \leq \frac{k}{2}\left[d\left(g(x), g\left(x^{*}\right)\right)+d\left(g(y), g\left(y^{*}\right)\right)\right] .
$$

Adding (25) and (26), we get

$$
d\left(g(x), g\left(x^{*}\right)\right)+d\left(g(y), g\left(y^{*}\right)\right) \leq k\left[d\left(g(x), g\left(x^{*}\right)\right)+d\left(g(y), g\left(y^{*}\right)\right)\right] .
$$

It follows that $d\left(g(x), g\left(x^{*}\right)\right)+d\left(g(y), g\left(y^{*}\right)\right)=0$ and so $g(x)=g\left(x^{*}\right)$ and $g(y)=g\left(y^{*}\right)$.

Second, let $(g(x), g(y))$ is not comparable to $\left(g\left(x^{*}\right), g\left(y^{*}\right)\right)$, then there exists $\left(g\left(u_{1}\right), g\left(v_{1}\right)\right)$ in $A_{0} \times A_{0}$ which is comparable to $(g(x), g(y))$ and $\left(g\left(x^{*}\right), g\left(y^{*}\right)\right)$. Since $F\left(A_{0}, A_{0}\right) \subseteq B_{0}$ and $g\left(A_{0}\right)=A_{0}$, there exists $\left(g\left(u_{2}\right), g\left(v_{2}\right)\right) \in A_{0} \times A_{0}$ such that $d\left(g\left(u_{2}\right), F\left(g\left(u_{1}\right), g\left(v_{1}\right)\right)\right)=d(A, B)$ and $d\left(g\left(v_{2}\right), F\left(g\left(v_{1}\right), g\left(u_{1}\right)\right)\right)=d(A, B)$.

Without loss of generality assume that $\left(g\left(u_{1}\right), g\left(v_{1}\right)\right) \leq(g(x), g(y))$, i.e., $g\left(u_{1}\right)<g(x)$ and $g\left(v_{1}\right) \geq g(y)$. Therefore $(g(y), g(x)) \leq\left(g\left(v_{1}\right), g\left(u_{1}\right)\right)$. Now, from Lemmas 3.7 and 3.8, we have

$$
\left\{\begin{array}{l}
\left(g\left(u_{1}\right), g\left(v_{1}\right)\right) \leq(g(x), g(y)), \\
d\left(g\left(u_{2}\right), F\left(g\left(u_{1}\right), g\left(v_{1}\right)\right)\right)=d(A, B), \\
d(g(x), F(g(x), g(y)))=d(A, B)=d(A, B),
\end{array}\right.
$$

then $g\left(u_{2}\right)<g(x)$ and in the same way

$$
\left\{\begin{array}{l}
\left(g\left(u_{1}\right), g\left(v_{1}\right)\right) \leq(g(x), g(y)) \\
d\left(g\left(v_{2}\right), F\left(g\left(v_{1}\right), g\left(u_{1}\right)\right)\right)=d(A, B) \\
d(g(y), F(g(y), g(x)))=d(A, B)=d(A, B)
\end{array}\right.
$$

then $g\left(v_{2}\right)>g(y)$.

Continuing this process, we obtain sequences $\left\{x_{n}\right\}$ and $\left\{y_{n}\right\}$ such that $g\left(u_{n}\right)<g(x), g\left(v_{n}\right)>$ $g(y)$

$$
\begin{aligned}
& d\left(g\left(u_{n+1}\right), F\left(g\left(u_{n}\right), g\left(v_{n}\right)\right)\right)=d(A, B), \\
& d\left(g\left(v_{n+1}\right), F\left(g\left(v_{n}\right), g\left(u_{n}\right)\right)\right)=d(A, B) .
\end{aligned}
$$

Since $F$ is a proximally $g$-Meir-Keeler type function, from Lemma 3.5, (23), (28),

$$
\exists k \in(0,1) ; \quad d\left(g\left(u_{n+1}\right), g(x)\right) \leq \frac{k}{2}\left[d\left(g\left(u_{n}\right), g(x)\right)+d\left(g\left(v_{n}\right), g(y)\right)\right], \quad \forall n \geq 0 .
$$

Similarly from Lemma 3.5, (24), (29), we have

$$
d\left(g\left(v_{n+1}\right), g(y)\right) \leq \frac{k}{2}\left[d\left(g\left(v_{n}\right), g(y)\right)+d\left(g\left(u_{n}\right), g(x)\right)\right], \quad \forall n \geq 0 .
$$

Adding (30) and (31), we have

$$
\begin{aligned}
& d\left(g\left(u_{n+1}\right), g(x)\right)+d\left(g\left(v_{n+1}\right), g(y)\right) \\
& \quad \leq k\left[d\left(g\left(u_{n}\right), g(x)\right)+d\left(g\left(v_{n}\right), g(y)\right)\right]
\end{aligned}
$$




$$
\begin{aligned}
& \leq k^{2}\left[d\left(g\left(u_{n-1}\right), g(x)\right)+d\left(g\left(v_{n-1}\right), g(y)\right)\right] \\
& \leq \cdots \leq k^{n+1}\left[d\left(g\left(u_{0}\right), g(x)\right)+d\left(g\left(v_{0}\right), g(y)\right)\right] .
\end{aligned}
$$

As $n \rightarrow \infty$, we get $d\left(g\left(u_{n+1}\right), g(x)\right)+d\left(g\left(v_{n+1}\right), g(y)\right) \rightarrow 0$, i.e., $g\left(u_{n}\right) \rightarrow g(x)$ and $g\left(v_{n}\right) \rightarrow$ $g(y)$. Similarly, we can prove $g\left(u_{n}\right) \rightarrow g\left(x^{*}\right)$ and $g\left(v_{n}\right) \rightarrow g\left(y^{*}\right)$. Hence, $g(x)=g\left(x^{*}\right)$ and $g(y)=g\left(y^{*}\right)$ and the proof is complete.

We shall illustrate the above theorem by the following example.

Example 3.15 Let $X$ be the real numbers endowed with usual metric and consider the usual ordering $(x, y) \leq(u, v) \Longleftrightarrow x \leq u, y \leq v$. Suppose that $A=[2,+\infty)$ and $B=(-\infty,-2]$. Then $A, B$ are nonempty closed subsets of $X$. Also, we have $d(A, B)=4$ and $A_{0}=\{2\}$ and $B_{0}=\{-2\}$.

Define the mappings $F: A \times A \rightarrow B$ and $g: A \rightarrow A$ as follows:

$$
F(x, y)=\frac{-x-y-4}{4} \text { and } g(x)=2 x-2 .
$$

Then $F$ and $g$ are continuous and $F(2,2)=-2$ and $g(2)=2$, i.e., $F\left(A_{0}, A_{0}\right) \subseteq B_{0}$ and $g\left(A_{0}\right)=A_{0}$.

Note also that the other hypotheses of Theorem 3.14 are satisfied, then there exists a unique point $(2,2) \in A \times A$ such that $d(g(2), F(g(2), g(2)))=4=d(A, B)$.

\section{Competing interests}

The authors declare that they have no competing interests.

\section{Authors' contributions}

All authors contributed equally and significantly in writing this paper. All authors read and approved the final manuscript.

\section{Acknowledgements}

This research was done while the first author was on a sabbatical leave at State University of New York at Albany (SUNYA): he wishes to thank SUNYA for its hospitality and Imam Khomeini International University for the financial support.

Received: 25 March 2015 Accepted: 17 June 2015 Published online: 08 July 2015

\section{References}

1. Banach, S: Sur les operations dans les ensembles abstraits et leur application aux equations integrales. Fundam. Math. 3, 133-181 (1922)

2. Meir, A, Keeler, E: A theorem on contraction mappings. J. Math. Anal. Appl. 28, 326-329 (1969)

3. Nieto, JJ, Rodriguez-Lopez, R: Contractive mapping theorems in partially ordered sets and applications to ordinary differential equations. Order 22, 223-239 (2005)

4. Suzuki, T: Meir-Keeler contractions of integral type are still Meir-Keeler contractions. Int. J. Math. Math. Sci. 2007 Article ID 39281 (2007). doi:10.1155/2007/39281

5. Suzuki, T: A generalized Banach contraction principle which characterizes metric completeness. Proc. Am. Math. Soc. 136, 1861-1869 (2008)

6. Suzuki, T: Fixed point theorems and convergence theorems for some generalized nonexpansive mappings. J. Math. Anal. Appl. 340, 1088-1095 (2008)

7. Bhaskar, TG, Lakshmikantham, V: Fixed point theorems in partially ordered metric spaces and applications. Nonlinear Anal. 65, 1379-1393 (2006)

8. Lakshmikantham, V, Ćirić, LB: Coupled fixed point theorems for nonlinear contractions in partially ordered metric spaces. Nonlinear Anal. 70, 4341-4349 (2009)

9. Samet, B: Coupled fixed point theorems for a generalized Meir-Keeler contraction in partially ordered metric spaces Nonlinear Anal. 72, $4508-4517$ (2010)

10. Fan, K: Extensions of two fixed point theorems of F.E. Browder. Math. Z. 122, 234-240 (1969)

11. Samet, B: Some results on best proximity points. J. Optim. Theory Appl. 159, 281-291 (2013)

12. Abkar, A, Gabeleh, M: Global optimal solutions of noncyclic mappings in metric spaces. J. Optim. Theory Appl. 153, 298-305 (2012)

13. Abkar, A, Gabeleh, M: Generalized cyclic contractions in partially ordered metric spaces. Optim. Lett. 6(8), 1819-1830 (2011) 
14. Eshaghi Gordji, M, Cho, YJ, Ghods, S, Ghods, M, Hadian Dehkordi, M: Coupled fixed-point theorems for contractions in partially ordered metric spaces and applications. Math. Probl. Eng. 2012, Article ID 150363 (2012)

15. Sadiq Basha, S, Veeramani, P: Best proximity pair theorems for multifunctions with open fibers. J. Approx. Theory 103, 119-129 (2000)

16. Abkar, A, Gabeleh, M: A note on some best proximity point theorems proved under P-property. Abstr. Appl. Anal. 2013, Article ID 189567 (2013)

17. Suzuki, T, Kikkawa, M, Vetro, C: The existence of best proximity points in metric spaces with the property UC. Nonlinear Anal. 71, 2918-2926 (2009)

18. Gabeleh, M: Proximal weakly contractive and proximal nonexpansive non-self mappings in metric and Banach spaces. J. Optim. Theory Appl. 158, 615-625 (2013)

19. Gabeleh, M: Best proximity point theorems via proximal non-self mappings. J. Optim. Theory Appl. 164, 565-576 (2015)

20. Karapinar, E, Agarwal, RP: A note on coupled fixed point theorems for $\alpha$ - $\psi$-contractive-type mappings in partially ordered metric spaces. Fixed Point Theory Appl. 2013, 216 (2013)

21. Sintunavarat, W, Kumam, P: Coupled best proximity point theorem in metric spaces. Fixed Point Theory Appl. 2012, 93 (2012)

22. Pragadeeswarar, $V$, Marudai, $M$, Kumam, $P$, Sitthithakerngkiet, $K$ : The existence and uniqueness of coupled best proximity point for proximally coupled contraction in a complete ordered metric space. Abstr. Appl. Anal. 2014, Article ID 274062 (2014)

\section{Submit your manuscript to a SpringerOpen ${ }^{\mathcal{O}}$ journal and benefit from:}

- Convenient online submission

Rigorous peer review

- Immediate publication on acceptance

- Open access: articles freely available online

- High visibility within the field

- Retaining the copyright to your article 